\title{
CALCULATION METHODOLOGY OF ENGINEERING RISK FACTOR AS A FUNCTION OFTIME AS A CONSTRAINT VARIABLE
}

\section{Zohair Khalaf Ismail, Ph.D. REM.}

Department of Chemical Engineering; Faculty of Engineering Technology

Al-Balqa Applied University; Marka-Amman, Box: 15008, Jordan

\section{Subhi K. Abderrezaq, Ph.D. REM.}

City University-Tricities, WA 99352 USA

\section{(Received June 15, 2006 Accepted June 28,2006 )}

Approach and implementation to access the risk factor associated with complex activities is the purpose of conducting analysis through "p,t" type tests. Complex activities, stiff opposition and inhospitable environment could be associated with increasing the risk factor. A driving simulator model was taken as a four cylinder type car with some more additional equipments fitted into it to simulate a realistic driving environment with a cell-phone as a distracter. The distracter was accomplished by the driving activity while using cell-phone, but the risk that drivers take upon the cell phone was unclear. The performance of drivers proved to be affected badly by a number of distracters that could lead easily to be evolved in crash. Also, the relationship between the difficulty level of a phone conversation and the resulting distraction use to be unclear. The study showed the effect that easy and difficulty cell phone conversations have on driving performance. Participants engaged in a cell phone conversations showed to have higher variations in accelerator pedal position, slower driving with more variations in speed, and a higher level of workload regardless of the difficulty level of the conversation.

It is found that the risk factors were 0.86 and 0.79 according to " $p$ " and " $t$ " tests (tables 3 and 4). Also, results constraints variables of same types of tests " $t, p$ " showed that certain increment from 0.68 to 0.80 suggesting that the additional stress reduced the variables leading to higher performance and increasing those towards higher risk factors.

KEYWORDS: Risk factor; Safety factor; Over load distraction. 


\section{INTRODUCTION:}

The risk management process is very important in resolving controversial issues and uncertainties in the decision making arena. Many significant problems have emerged in society's attempt to manage complex activities and risks that point to the decision-making structure. One of the problems is the question concerning the ability of man-power and information processing resources to cope with technical advances and demands of risk assessments [1]. Other problems are concerned with the conditions under which organizations should modify decision making structure with respect to risk. An ambiguous and often unknown answer retards the agency's ability to deal with and manage high-risk and complex situations.

Specialists in the field of risk analysis have emphasized three important interrelated areas to provide a uniform framework for decision making regarding management of complex activities involving risk. The three areas include the probability of risk and quantification of risk consequences, and the human judgments and reactions toward risk as well as the integration between the above two areas to evaluate trade-offs among risk alternatives [2]. The process of integrating the above three areas into the decision-making process itself is called risk management.

One of the key aspects of managing risks is to treat managing of complex activities as treating and managing crisis. The field of crisis management differs from risk management in that risk consequences have already been realized during a crisis. The two concepts of management have a number of decision making characteristics in common such as the need to reduce or avoid consequences under conditions of uncertainty. An approach to the relationship of organizational behavior to catastrophic or sudden events emerged in the context of general response of organization to their environment [3]. Organizations may differentiate their structures as means of adapting the crisis. In mid-1970s, organizational response to crisis began to unit in various decision models primarily trying to explain responses and predict or prescribe solutions. For instance, [4], outlined the steps in decision making in organizations following the emergence and resolution of crisis and hypothesized a casual sequence of events as a model of decision making under crisis conditions.

Herman developed a model of the behavior of organizations in a crisis. Based on the concept of crisis as: (1) surprise to decision makers; (2) a short time frame for decision making; and (3) embodying a threat to goals and policies. This model linked the above three characteristics of crisis to the following aspects of decision making: the number of decision makers involved, the 
number of alternatives proposed to deal with the problem, the effectiveness and the rate of communication within the system itself and among the system agencies (internal communication), the effectiveness and the rate of communication among agencies of one nation (external communication) and frequency with which decision makers take action. The experimental conditions of one of the activities were examined as a function of time for different ages.

\section{EXPERIMENTAL METHODS:}

Each of the $20^{\text {th }}$ participants performed three driving runs; each run assigned a level of conversation. Runs lasted approximately 10 minutes when driven at 35 $\mathrm{mph}$, and each single run was broken into two paths separated by a break, in that way creating six total driving paths.

- Experimental Control Conditions:

1- All of the 20 participants had a valid driver license.

2- All of the 20 participants had at least 3 years of experiences.

3- All of the 20 participants had 0 times of experience with the driving simulator.

4- Ambient traffic was present throughout the driving environment and was controlled so that driving conditions remained constant for all the 20 participants.

5- Cars act as distracters to drivers of pull-out type hazardous driving were parked on the side of the road.

6- Cars acted as distracters to drivers of suddenly changing direction type hazardous driving.

7- Ambulance acted as a distracter that runs a red light in the front of the driver.

8- For each difficulty level, questions were presented in two different random orders so that half of the participants experienced each order.

9- The experimenter asked the next question on the list after the participant evolved in the run finished his or her response till the end of the trial.

10- Questions considered to have a particular difficulty level were asked together during a continuous driving trial.

11- The two types of questions were blocked, not intermixed during the experiment.

12- All the 20 participants completed demographic and general driving background questionnaires before being seated in the simulator. 
Table 1: Participants Characteristics:

\begin{tabular}{|c|c|c|c|c|}
\hline Participants & Age & $\begin{array}{c}\text { mean age } \\
\text { (yrs.) }\end{array}$ & $\begin{array}{c}\text { mean driving } \\
\text { experience } \\
\text { (yrs.) }\end{array}$ & Range (yrs.) \\
\hline Male & $20-30$ & 21.5 & 3.6 & 19 to 34 \\
\hline Female & $30-40$ & 21.5 & 3.6 & 19 to 34 \\
\hline
\end{tabular}

The 20 participants $(10$ males, 10 females, mean age $=21.5$ years, range $=19$ to 34 years) were given monetary compensation for their participation. All participants had a valid driver license and at least two years of driving experience (mean driving experience $=3.6$ years).

Further research indicated that the time frame for decision making and embodying a threat to goals and policies were the major key aspects of crisis that were related to the five decision-making characteristics, rather than surprise to decision makers. In addition, the significance of threat and time estimation by the participants in the crisis was greater than when outside observers estimate it. Other researcher's associate crisis with certain management problems similar to those identified by Hermann [5] such as scarce information, communication problems and the changing character of the role players. A model relating administrators' perception of crisis to a difference they perceive between the crisis situation and some expected norm or standard was developed by Billings, [6]. Based on this research, the frame of reference of crisis managers perceived disruption rather than the actual disruption. that.

The relevance of the risk perception literature to risk and crisis management is in gaining insights into the behavior of the risk managers during the process of decision making. The individuals who are involved in decision-making process about risks associated with managements such as regulators, policy makers and financial planners are called risk managers. Lack of surveys of attitudes and perceptions of federal regulators towards risk in literature exists. Comprehensive studies of the risk perceptions of other categories of individuals are needed.

\section{MEASUREMENTS:}

Methodology conducted throughout this research was carried on according to Michael et all [8]. Measures were included for the mobility and safety objectives of the primary driving task. Measurements of speed maintenance, lane-keeping at a frequency of $4 \mathrm{~Hz}$, and crash avoidance at $20 \mathrm{~Hz}$ were 
computed for path sections that did not include intersections or curves. However; the following variables were computed based on the recorded data:

-Speed maintenance:

1- Accelerator position variability, based on the standard deviation of the accelerator pedal position $(0=$ released to $1=$ fully depressed $)$.

2 - Speed variability, based on the standard deviation of driving speed (mph).

3 - Average speed, based on mean driving speed ( $\mathrm{mph}$ ).

- Lane keeping:

1 - Steering offset, calculated as the standard deviation of the distance that the top-most point of the steering wheel moved from center (degrees, negative for left of center and positive for right of center).

2 - Mean lateral speed, calculated as the mean of the lateral distance that the participant's car traveled per second (feet per second).

- Crash avoidance:

Collisions with other vehicles recorded as a binary variable and presented as a percentage of total events. Reaction time (RT), calculated in seconds (s) as the time elapsed from the event trigger to the first occurrence of one the following three responses:

1- An accelerator position equal to 0 , indicating pedal release.

2. A braking position greater than 0 , indicating brake activation.

3. A change in steering angle more than three standard deviations above or below the average steering angle of that participant on straight-aways. A change in steering angle of this magnitude was taken to indicate the initiation of a turning maneuver. Before applying this rule, steering response values were run through a digital, low-pass filter that removed changes greater than $2 \mathrm{~Hz}$ in frequency, which were thought to reflect noise rather than actual steering movements.

\section{PROCEDURE:}

In this experiment both types of conversation tasks (easy and difficult) were performed and conducted in a continuous manner from the start to the finish of a run. Participants were addressed to the driving simulator system by driving two practice sessions. The first session allowed participants to get used to the simulator controls system, and the second allowed them to become familiar with steering and turn instructions from the simulator equipped with automated visual and auditory cues. For example, if a participant missed a turn, he will be informed by the simulator to stop, and the experimenter directed them back onto the correct path. After both practice sessions were completed, participants 
walked to a nearby table and completed the first workload test. The ultimate speed maintenance was around $35 \mathrm{mph}$. The speedometer turns yellow if participants drove over $40 \mathrm{mph}$ and red if above $45 \mathrm{mph}$. At the red signal the system will inform the participant to slow down [7].

\section{RESULTS AND DISCUSSIONS:}

\section{- Mental workload data:}

The workload ratings data were checked .. These data reflected the overall effort required for the driving and the conversation tasks, the subjective type mental effort was higher in the presence of a conversation relative to no conversation, but there was no significant difference in reported effort between the conversation levels while driving. Questions in this experiment were designed to reflect different levels of difficulties, and were intended to entail the same response time so that both levels of conversation could have the same number of responses in a given time period (response rate). The data expresses the fact the there was not a significant difference between the time participants took to answer the easy and difficult questions and that engagement of a driver in a conversation did increase the effort to be handled while driving [7]. The above may be observed by results reported in table 2 .

Table 2: Numbers of questions answered in each conversation condition.

\begin{tabular}{|c|c|c|c|c|}
\hline \multirow{2}{*}{ Parameters } & \multicolumn{2}{|c|}{ Easy } & \multicolumn{2}{c|}{ Difficult } \\
\cline { 2 - 5 } & Mean & Standard Error & Mean & 0.95 \\
\hline All participants & 20.22 & 1.05 & 21.35 & 1.27 \\
\hline Female & 18.50 & 1.45 & 18.88 & 1.20 \\
\hline Male & 23.55 & 1.37 & 23.94 & \\
\hline
\end{tabular}

\section{Practice effects:}

The performance of participants on later trials may be affected by the knowledge and experience gleaned from earlier trials. A certain analysis was conducted to check for these effects, and to compare the performance of participants from the first to the third driving trials for all variables except collisions. The performance in first driving trial is given a weight of -1 , a weight of 1 to the last trial, and the second trial was given a weight of 0 . As depicted from table 3; none of the variables considered showed any significant practice effects. The reaction time (RT) to the hazard events improved significantly with experience. The value of one-tailed " $t$ " test $=2.35$, and $P=$ .013. This concludes that participants became more cautious to the hazardous conditions as the experiment progressed. 
Table 3: Analysis results of practice effects." t, p-type tests are included".

\begin{tabular}{|c|c|c|c|c|c|c|c|c|c|}
\hline \multirow{2}{*}{ Parameters } & \multirow[t]{2}{*}{$\begin{array}{c}\text { Dependant } \\
\text { Variable }\end{array}$} & \multicolumn{6}{|c|}{ Number of trials } & \multicolumn{2}{|c|}{$\begin{array}{l}\text { Improvements Level } \\
\text { Trail"1"to "3" }\end{array}$} \\
\hline & & Mean & SE & Mean & SE & Mean & SE & " $t$ " test & $" p "$ test \\
\hline Speed & AV & 0.040 & 0.003 & 0.043 & 0.003 & 0.043 & 0.003 & 0.325 & 0.362 \\
\hline Maintenance & SV & 0.615 & 0.028 & 0.685 & 0.027 & 0.055 & 0.030 & 0.855 & 0.167 \\
\hline & AS & 46.5 & 0.45 & 45.72 & 0.401 & 45.85 & 0.422 & 1.415 & 0.068 \\
\hline Lane Position & SV & 2.22 & 0.255 & 2.25 & 0.35 & 1.90 & 0.155 & 0.565 & 0.268 \\
\hline Maintenance & MLS & 0.075 & 0.005 & 0.078 & 0.004 & 0.082 & 0.004 & 0.257 & 0.362 \\
\hline $\begin{array}{c}\text { Crash } \\
\text { Avoidance }\end{array}$ & RT & 0.380 & 0.168 & -.001 & 0.222 & -0.355 & 0.201 & 2.35 & 0.013 \\
\hline $\begin{array}{c}\text { Mental } \\
\text { Workload }\end{array}$ & RSME & 39.5 & 4.115 & 38.85 & 4.232 & 36.15 & 4.120 & 0.632 & 0.252 \\
\hline Risk Factor & All & 20.5 & 3.95 & 25.52 & 10.5 & 17.61 & 11.8 & 0.86 & 0.79 \\
\hline
\end{tabular}

AV: Accelerator Variability. SV: Speed Variability. AS: Average Speed. SO: Steering Variability. MLS: Mean Lateral Speed. RT: Reaction Time. RSME: Rating Scale of Mental Effort. SE: Standard Error.

\section{Speed Maintenance (Mobility):}

Variables that directly influence the speed maintenance were also tested in the experiment. Conversation effects, difficulty effects, lane position maintenance, and crash avoidance are the main parameters given in table "4".

Table 4: Analysis results for all dependant variables." t, p-type tests are included".

\begin{tabular}{|c|c|c|c|c|c|c|c|c|c|c|}
\hline \multirow{3}{*}{ Parameters } & \multirow{3}{*}{$\begin{array}{c}\text { Dependant } \\
\text { Variable }\end{array}$} & \multicolumn{5}{|c|}{ Number of trials } & \multicolumn{4}{|c|}{ Contrast effects analysis } \\
\hline & & \multicolumn{2}{|c|}{1} & \multicolumn{2}{|c|}{2} & 3 & \multicolumn{2}{|c|}{ Conversation } & \multicolumn{2}{|c|}{ Difficulty } \\
\hline & & Mean & SE & Mean & SE & Mean & $" t "$ & "p" & $" t "$ & $" p "$ \\
\hline \multirow{3}{*}{$\begin{array}{c}\text { Speed } \\
\text { Maintenance }\end{array}$} & $\mathbf{A V}$ & 0.041 & $\mathbf{0 . 0 3 3}$ & 0.055 & 0.224 & 0.0080 .043 & 1.015 & 0.0335 & 1.289 & 0.113 \\
\hline & SV & 1.155 & 0.068 & 1.338 & 0.065 & 0.062 & 2.352 & 0.113 & 1.255 & 0.118 \\
\hline & $\mathbf{A S}$ & 46.75 & 0.365 & 44.25 & 0.446 & $44.63 \quad 0.401$ & 2.301 & 0.0135 & 1.127 & 0.127 \\
\hline \multirow{2}{*}{$\begin{array}{c}\text { Lane } \\
\text { Position } \\
\text { Maintenance } \\
\end{array}$} & SV & 1.68 & 0.256 & 2.302 & 0.392 & $2.105 \quad 0.105$ & 0.788 & 0.195 & 1.135 & 0.126 \\
\hline & MLS & 0.080 & 0.006 & 0.074 & 0.005 & $0.084 \quad 0.004$ & 1.005 & 0.149 & 0.222 & 0.0398 \\
\hline Crash & RT & 0.380 & 0.168 & -0.001 & 0.222 & $-0.355 \quad 0.201$ & 0.365 & 0.352 & 0.485 & 0.298 \\
\hline Avoidance & $\mathbf{C}$ & $\mathbf{5 0 \%}$ & 0.105 & $47.25 \%$ & 0.105 & $47.25 \% \quad 0.105$ & 0.105 & 0.138 & 0.000 & 0.495 \\
\hline $\begin{array}{c}\text { Mental } \\
\text { Workload }\end{array}$ & RSME & 30.08 & 3.522 & 40.23 & 3.653 & $39.73 \quad 4.628$ & 2.959 & 0.0029 & 0.0578 & 0.436 \\
\hline Risk Factor & All & 22.5 & 4.00 & 27.25 & 13.65 & $18.52 \quad 9.88$ & 0.68 & 0.65 & 0.76 & 0.80 \\
\hline
\end{tabular}

AV: Accelerator Variability. SV: Speed Variability. AS: Average Speed. SV: Steering Variability. MLS: Mean Lateral Speed. RT: Reaction Time. RSME: Rating Scale of Mental Effort. SE: Standard Error. C: Collisions. 
The data concludes that engaging in a conversation over a cell phone significantly influenced some of the parameters tested, such as accelerator position, speed variability, and mean speed, at the same time did not significantly influence steering variability or mean lateral speed. Also, there was no significant effect of the cell phone conversations with respect to reaction time to hazard events or percentage of events resulting in a collision.

Parameters tested including the presence of different difficulties of cell phone conversation did not significantly influence accelerator position variation, speed variability, or mean speed. The results showed that the presence of different difficulties of cell phone conversation did not significantly influence steering variability or mean lateral speed. However, the impairment of mobility parameter was the most consistent that seems effected in the presence of any cell phone conversation.

The higher workload associated with the cell phone conversations coincided with slower average speeds and larger speed variation. There was also some indication of increased accelerator position variability. In contrast, there were no significant effects of conversation difficulty on driving performance. Consequently, this research study does not support the hypothesis that level of conversation difficulty can impact driving performance. The main impairment effect occurs during any conversation, relative to driving without conversing. The MANOVA was conducted to test the effect of conversation level which was not significant, exact $F(4,20)=1.38, p=.212$. In addition, a separate contrast analysis was conducted for each of the hypothesized effects for the lane position maintenance variables. Further action is required; alternatives for managing the risk must be identified. These alternatives of managing the risk can be "regulatory" or "nonregulatory". Regulatory refers to alternative government actions such as standard setting. Nonregulatory refers to actions such as legal remedies of voluntary standards.

A decision analysis is required in order to determine the appropriate approach for managing a risk. The nature of the problem, characteristics of each management alternatives and the estimated outcome of each hazard must be accounted for in order to make acceptable decision. Most of The times, the management of complex problems is dominated by uncertainty. The exact hazard and their probabilities of occurrence will be unknown. The decision analysis must consider the uncertainties due to the fact that the efficiency of each risk management alternative can be estimated only roughly.

The next step is to decide on the management approach and goal given the existence of political and other constraints and barriers. Regardless of the goal 
and approach which are decided upon, many people will believe that the wrong decision was made. Such people may challenge the decision politically and legally or refuse to live by the decision made. Thus, before a risk management strategy is achieved, the legal and political challenges must be resolved and the level of acceptance of the decision must be reached [8]. The next step is the actual implementation of the risk management strategy. The nature of the hazards and probabilities of occurrence will be determined with greater certainty and new hazards are most likely to be discovered [9]. It's possible that the management strategy might be shown to be inefficient and ineffective. Therefore, this stage could lead to going back all the way to hazard identification and a reconsideration of the problem.

The final stage consists of determination of how well the strategy is working and how costly it has proven to be by monitoring the management strategy. This monitoring step might turn up new hazards, new estimates of the probabilities of occurrence and other related problems which may lead to a recycling through the entire set of steps [2].

\section{CONCLUSIONS:}

Because of the complexity of large scale activities, there is an increased possibility of problems arising with each of its phases. Each of the problems is unique and has to be resolved accordingly. Also, every solution to a specific problem carries uncertainties and risks that must be acknowledged and appropriately addressed immediately. The management of complex activities has many risks associated with implementing it and that involves complicated scientific analysis and difficult value judgment which interacts with many fundamental conceptions and many social judgments about the rights of individuals and society.

The behavior of individual decision makers and groups in a state of crisis has many similarities to their decision-making behavior about complex and risk management. Some of these similarities are: a high degree of uncertainty, communication problems and information utilization.

Decision makers usually use reference points against what they evaluate risk or crisis outcomes and alterations in the administrative arrangements take place when decisions are being made.

According to this study the findings suggest that having any distracter such as that using a hands-free cell phone while driving can increase the risk factor which may cause decrements in performance, while also leading to decreased 
average speeds which increases the risk of traffic crashes (see tables 3 and 4); where the risk factor was 0.86 and 0.79 according to "p" and "t" tests. This study confirms that regardless of the intensity of the distracting factor, performance will be affected by this attentiveness (attention) distraction. The driving decrements found in this study due to both types of distracters (conversation), coupled with the lack of any effect of conversation difficulty, strengthen the belief that even casual conversations may be unsafe and hazardous. Analysis results for all dependant variables." t, p" type tests showed certain increment from 0.68 to 0.80 by results carried on the contrast effects analysis. Therefore, additional stress of phone conversations for example by long-term higher workloads or setting reduced performance goals.

\section{REFERENCES}

[1] Charles H. Kepner and Benjamin B. Tregoe, "The Rational Manager",1976, Kepner Tregoe, Inc., Princeton, New Jersey.

[2] "Contemporary Issues in Risk Analysis", Volume 1: "Risk Evaluation and Management", Vicent T. Covello, Joshua Menkes and Jeryl Mumpower, Eds., 1986, Plennum Press, New York.

[3],"Managing for Excellance, the Guide to Developing High Performance in Contemporary Organizations", 1984. David L. Bradford and Allen R. Cohen 1984.

[4] Turner, B.A., "The Organizational and Interorganizational Development of Disasters," ASQ, 21 (September1976), 378-397.

[5] Hermann, C.F., "Threat, Time and Surprise: A Simulation of International Crisis."In: International Crisis: Insight from Behavior Research, edited by C.F. Hermann. New York, N.Y.: The Free Press, 1972, 187-211.

[6] Billings, R.S., T.W. Maliburn, and Schaalman,"A Model of Crisis Perception: A Thoeretical and Empirical Analysis," ASQ, 25(June 1980), 300-316.

[7] Michael E. Rakauskas, Lee J. Gugerty, \& Nicholas J. Ward. Journal of safety

research; 2004, 453-464.

[8] "Quality Educational System for the Individual", 1988, Philip Crosby Associates, Inc., Winter Park, Florida.

[9] "In Search of Excellence, Lessons from America's Best-Run Companies", 
Thomas J. Peters and Robert H. Waterman, Jr., 1982, Warner Books, New York

\section{نموذج إحصائي رياضي لتطبيق (P, t ) test) بلالة الزمن}

هذا النموذج الإحصـائي الرياضـي يحدد العامل المؤثر بدلالـة الزمن لتقليص المخـاطر الناتجة والمرتبطة باستخدام جهاز أو إجراء نشـاط معين هندسي أم بيئي. وتم استخدام النموذج الإحصائي test ( ) p p ) ونم تحديد نشاط و إجراء عرضي مألوف لتطبيق هذاء النمـوذج الإحصـائي الرياضـي على نشـاط معين وتم تحديد المتغيرات والثوابت الواجب التب توفرها للحصول على أكبر عامل أمان ممكن بدلالة الزمن . 